\title{
Turşu sanayisine uygun tatlı süs biberi çeşitlerinin geliştirilmesine yönelik melezleme ıslahı çalışmaları
}

Crossbreeding studies of sweet ornamental pepper suitable for pickle industry

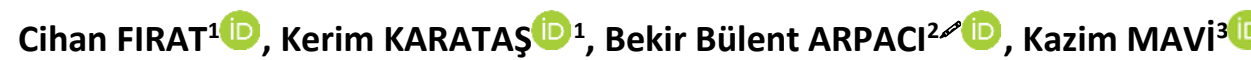

${ }^{1}$ Doğu Akdeniz Geçit Kuşağı Tarımsal Araştırma Enstitüsü Müdürlüğü, Onikişubat, Kahramanmaraş.

${ }^{2}$ Çukurova Üniversitesi, Ziraat Fakültesi, Bahçe Bitkileri Bölümü, Balcalı, Adana.

${ }^{3}$ Hatay Mustafa Kemal Üniversitesi, Ziraat Fakültesi, Bahçe Bitkileri Bölümü, Antakya.

MAKALE BILGISI / ARTICLE INFO

\section{Makale tarihçesi / Article history:}

DOI: $10.37908 /$ mkutbd.961983

Geliş tarihi /Received:03.07.2021

Kabul tarihi/Accepted:06.09.2021

\section{Keywords: \\ Capsicum annuum, Capsicum chinense, ornamental pepper, pickle, hotness.}

\footnotetext{
Corresponding author: B.Bülent ARPACl

$\bowtie$ : bbarpaci@cu.edu.tr
}

\section{ÖZET / A B STRACT}

\begin{abstract}
Aims: The aim of this study is to develop capsaicinoid-free sweet pickled pepper lines by intra-and inter-specific combination.

Methods and Results: In this study, high yielded, non-pungent, single bite, ornamental pepper lines have been improved, by pedigreecontrolled single selection breeding method through combination 2 exterior ornamental pepper varieties (Biquinho and Santos Flame) and 3 sweet pepper genotypes (MKÜ-69, F66-SB, and CHF-1). The capsaicin contents of the parents, hybrid, and developed pepper lines were determined by High-Pressure Liquid Chromatography and converted to Scoville Heat Unit (SHU). It has been determined that there is no hotness in the Santos Flame variety, but in the Biquinho variety had a low level (396 SHU) hotness cannot be sensed, and a very high hotness (15733 SHU) occurs in the fruits of $F_{1}$ plants. Due to the presence of the hotness in the fruits obtained from the $F_{2}$ generation, this combination has been discontinued. Four $F_{6}$ pickling sweet ornamental pepper lines have been improved from combinations of Santos Flame cultivar was used as the male, and MKÜ-69, F66-SB, and CHF-1 genotypes were used as female parents.

Open-pollinated variety candidate no. 8 developed as pickled sweet ornamental pepper from Santos Flame and MKÜ-69, F66-SB and CHF-1 combinations have $60 \mathrm{~cm}$ plant height, $52.6 \mathrm{~mm}$ fruit length, $9.0 \mathrm{~mm}$ fruit width, and $2.2 \mathrm{~g}$ fruit weight. The number of fruits was determined as 274 fruit per plant and the average yield was $598 \mathrm{~g} \mathrm{plant}^{-1}$. The candidate number 9 line has the characteristics of $70 \mathrm{~cm}$ plant height, $36.5 \mathrm{~mm}$ fruit length, $13.1 \mathrm{~mm}$ fruit width, and $2.9 \mathrm{~g}$ fruit weight. The average fruit number is 263 fruit per plant, the average yield is $759 \mathrm{~g} \mathrm{plant}^{-1}$ and 3581 $\mathrm{kg} \mathrm{da} \mathrm{d}^{-1}$

Conclusions: Considering the hotness trait in pepper genetically distant parents which are similar in terms of the character desired to be introgressed generate segregation.

Significance and Impact of the Study: As a result of the study, sweet ornamental pepper lines, which can be consumed in single bite without pungency components, have been developed as an alternative to pickled hot pepper varieties.
\end{abstract}

Atıf / Citation: Cihan F, Karataş K, Arpacı BB, Mavi K (2021) Turşu sanayisine uygun tatlı süs biberi çeşitlerinin geliştirilmesine yönelik melezleme ıslahı çalışmaları. MKU. Tar. Bil. Derg. 26(3) : 679-691. DOI: 10.37908/mkutbd.961983 


\section{GíRiş}

Dünya'da 2019 yılında üretilen toplam 42 milyon ton biberin 19.3 milyon tonu Çin'de üretilmiştir. Türkiye yaklaşık 2.6 milyon ton biber üretimi ile Meksika'dan sonra 3. sırada yer almaktadır (Anonymous, 2021). Taze olarak tüketilmesinin yanı sıra gıda sanayinde kullanılan biber meyveleri; kurutularak, öğütülerek, konserve, salça veya turşuya işlenerek değerlendirilmektedir. Bu değerlendirme şekillerinden turşular, içerdikleri aroma bileşikleri ve iştah açıcı özellikleri nedeni ile tercih edilmektedir. Biberin turşu halinde işlenmesi yıl boyunca tüketimine olanak sağlamaktadır. Türkiye'de 2019 yılında toplam 175735 ton turşu satışı gerçekleştirilmiştir (Anonim, 2020). Tüm biber tipleri turşu yapımına uygundur (Bosland ve Votava, 2012). Ancak tüketim tercihleri düşünüldüŭünde biber turşularının, küçük, az tohum içeren ve tek seferde tüketilecek büyüklükte olması istenmektedir.

Biber meyveleri değişik acılık düzeylerine sahiptir ve meyvede acılığın bulunup bulunmaması tüketimde tercih sebeplerindendir. Biberde bulunan acllık maddeleri ilk olarak Thresh (1846), tarafından ekstrakte edilmiş ve kapsaisin olarak isimlendirilmiştir. Kapsaisinoidler Capsicum cinsi içerisinde acılığa neden olan ve önemli bir kalite kriteri olarak nitelendirilen kimyasal bir bileşiktir. Kapsaisin, dihidrokapsaisin, nordihidrokapsaisin, norkapsaisin, homokapsaisin, nornorkapsaisin ve homodihidrokapsaisin kapsaisinoidlerin en önemlileridir (Greenleaf, 1986; Collins ve Bosland, 1994). Biberlerde kapsaisinden kaynaklanan acılık ölçümlerinde kullanılan ilk test 1912 yılında Wilbur Scoville tarafından geliştirilmiştir. Günümüzde dünyanın en acı biber çeşitleri 1019687 SHU acılık değeri ile Bhut Jolokia (Bosland ve Baral, 2007) ve 2009231 SHU acılığa ulaşan Trinidad Moruga Scorpion'dur (Bosland ve ark., 2012). Acl olan biber genotipleri içerisinden kapsaisin içermeyen $C$. annuum (Yazawa ve ark., 1989), C. chinense (Reifschneider ve ark., 2013) ve C. frutescens (Bosland ve Coon, 2020) türlerine dahil olan çeşitler geliştirilmiştir. Bu çalışmada kombinasyon ıslahı ve döl kontrollü teksel seleksiyon yöntemi ile geliştirilen turşu sanayisine uygun, tek seferde tüketilebilen, acı olmayan ve verimi yüksek süs biberi hatlarının özellikleri verilmiştir.

\section{MATERYAL VE YÖNTEM}

Ebeveynlerin seçimi ve ıslah programının oluşturulması Çalışmada kullanılan ebeveynler melezleme ve kendileme sonrası oluşturulan $\mathrm{F}_{2}$ popülasyonları Çizelge 1.'de verilmiştir.

Çizelge 1 Islah programında kullanılan ebeveynler ve melezleme ve kendileme sonrası oluşturulan $F_{2}$ popülasyonları Table 1 Parents used in the breeding program and $F_{2}$ populations improved by crossbreeding and selfing

\begin{tabular}{lllll}
\hline Baba ebeveyn & & Ana Ebeveyn & & Melez populasyonlar \\
\hline Biquinho & $\otimes$ & Santos Flame & $\oplus$ & F2 ${ }_{\mathrm{A}}$ \\
\hline CHF-1 & $\otimes$ & Santos Flame & $\oplus$ & F2 \\
\hline F66-SB & $\otimes$ & Santos Flame & $\oplus$ & F2 \\
\hline MKÜ-69 & $\otimes$ & Santos Flame & $\oplus$ & F2 \\
\hline
\end{tabular}

$\otimes:$ Melezleme $\quad \oplus:$ Kendileme

Capsicum annuum türüne ait açık tozlanan Santos Flame çeşidinin bitki yüksekliği $15-17 \mathrm{~cm}$ arasındadır. $\mathrm{Acl}$ olmayan meyvelere sahip olgun meyve rengi açık turuncu, meyve uzunluğu 5-6 cm ve meyve genişliği 1$1.5 \mathrm{~cm}$ 'dir (Şekil 1).

Capsicum chinense türüne giren açık tozlanan Biquinho çeşidinin bitki boyu $40-45 \mathrm{~cm}$ dir. Acı olmayan konik tipte meyveler oluşturmaktadır. Olgun meyve rengi kırmızı, meyve uzunluğu $2.5-2.8 \mathrm{~cm}$ ve genişliği $1.5 \mathrm{~cm}$ dir. Brezilya ve İspanya gibi Avrupa ülkelerinde meyveler kırmızı renk aldıktan sonra hasat edilmekte ve turşuluk olarak kullanılmaktadır (Reifschneider ve ark., 2013). 


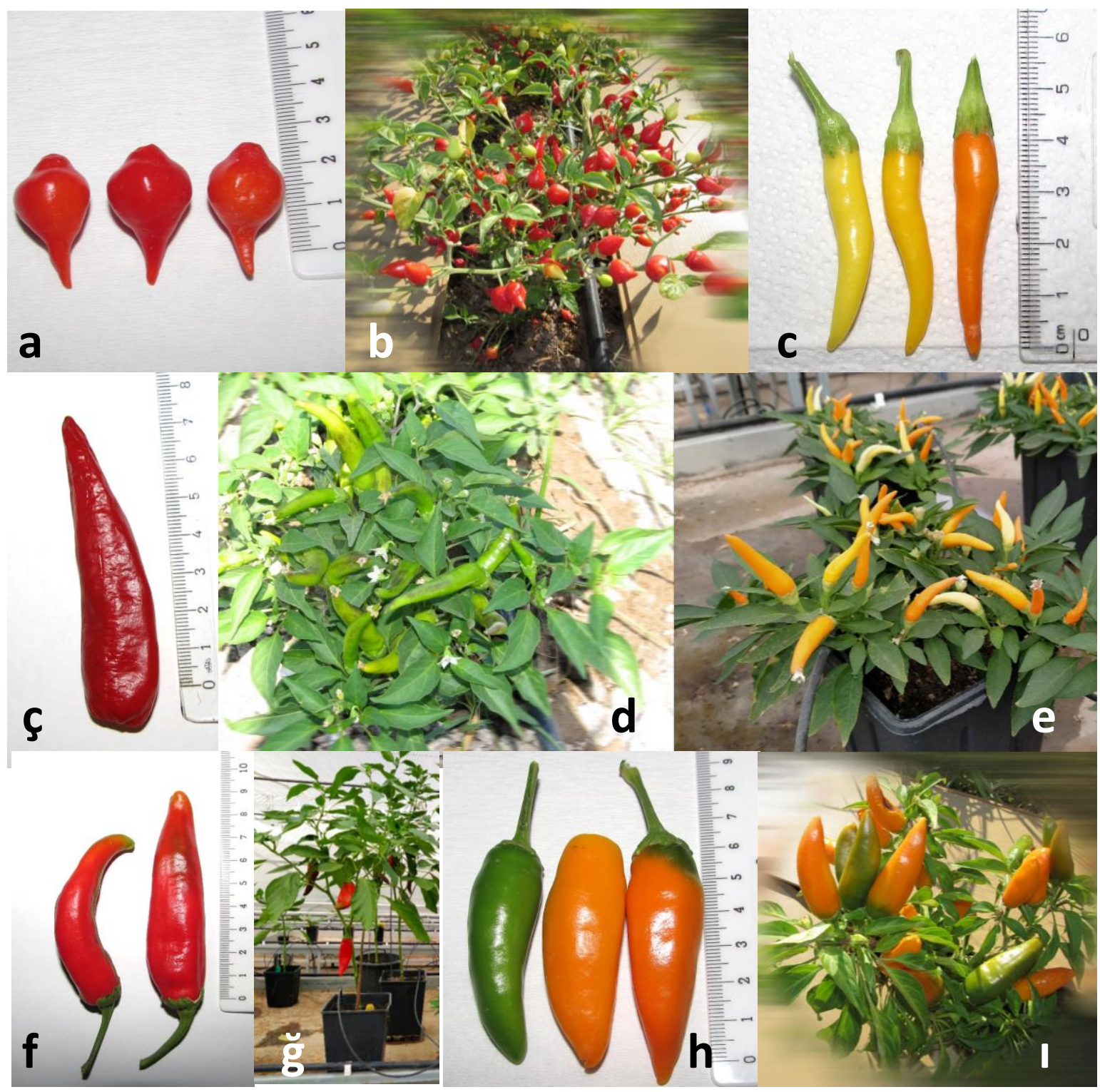

Şekil 1. Çalışmada ebeveyn olarak kullanılan Biquinho (a: meyve b: bitki), Santos Flame (c: meyve e: bitki), CHF-1 (ç: meyve d: bitki), F66-SB (f: meyve ğ: bitki) ve MKÜ-69 (h: meyve I: bitki) genotiplerinin görünümleri.

Figure 1. Appearance of Biquinho (a: fruit b: plant), Santos Flame (c: fruit e: plant), CHF-1 (d: fruit d: plant), F66-SB (f: fruit ğ: plant), and MKÜ-69 (h: fruit I: plant) used as parents in the study Islah programı ve tartılı derecelendirme puanları.

Islah programına 2013 yılında Santos Flame (A) ve Biquinho (B) çeşitlerinin resiprokal melezlenmesi ile başlanmış, 2014 yılında da Santos Flame (A) ve CHF-1

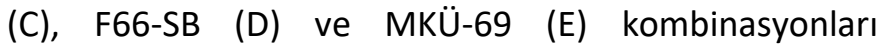
programa eklenmiştir. Oluşturulan $F_{3}$ populasyonlarından seçilen bireyler ıslah programının 7. yılına (2019) kadar kendilenmiş ve bitkisel özellikler döl kontrolü ile izlenmiştir. Programın 8. yılında (2020) seçilen genotipler verim denemesine alınmıştır (Şekil 2). 


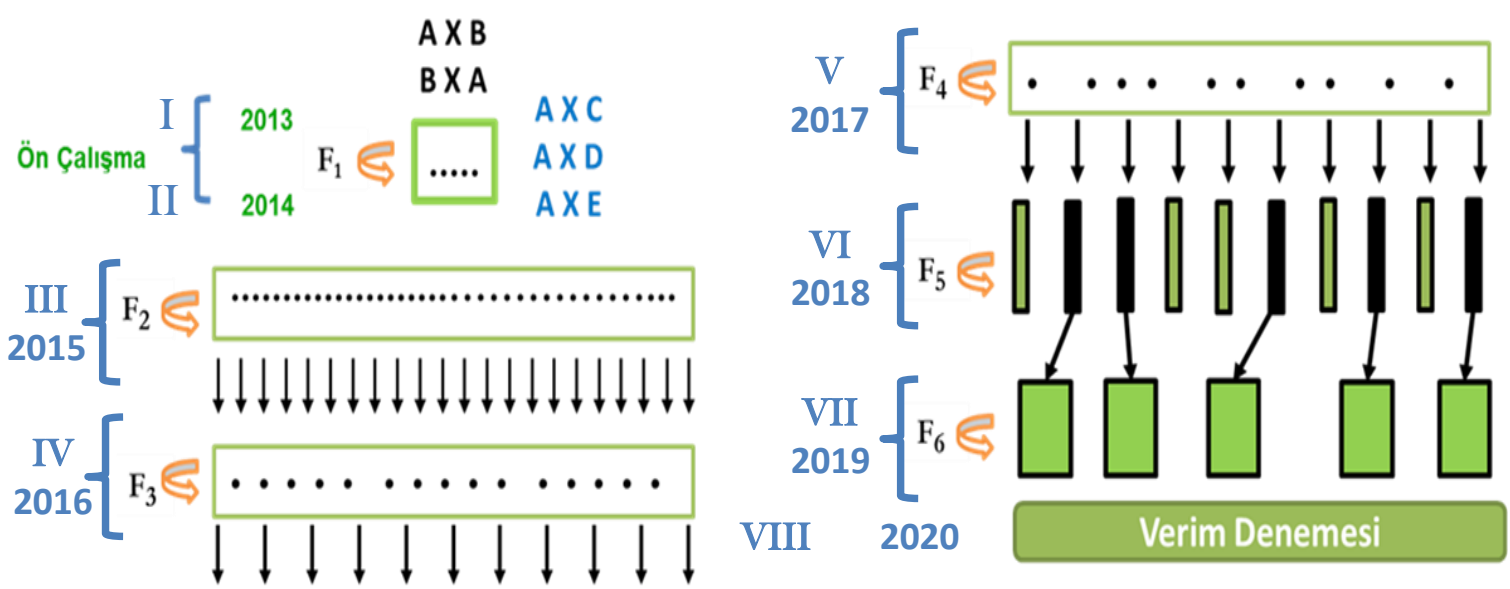

Şekil 2. Melezleme ve kendileme şeması [Santos Flame (A), Biquinho (B), CHF-1 (C), F66-SB (D) ve MKÜ-69 (E)]. Figure 2. Hybridization and selfing scheme [Santos Flame (A), Biquinho (B), CHF-1 (C), F66-SB (D) and MKÜ-69 (E)].

Islah programının 7. yılında (2019) $\mathrm{F}_{6}$ generasyonundan elde edilen veriler tartılı derecelendirmeye tabi tutulmuş sınıf puanları ve göreceli puanları (Çizelge 2.) esas alınarak hatların toplam puanları hesaplanmıştır.
Değerlendirmede bitki yüksekliği $50 \mathrm{~cm}$ 'den uzun, olgun meyve rengi turuncu, meyve uzunluğu $6 \mathrm{~cm}$ ve altında, toplam meyve sayısı yüksek olan hatlara öncelik verilmiştir (Çizelge 2).

Çizelge 2. Seleksiyon kriterleri, oluşturulan sınıflar, sınıf puanları ve bunlara verilen göreceli puan değerleri

Table 2. Selection criteria, classes, class scores and their relative values

\begin{tabular}{|c|c|c|c|}
\hline Seleksiyon Kriterleri & Oluşturulan Sınıflar & $\begin{array}{l}\text { Sinıf Puanları } \\
\text { (SP) }\end{array}$ & Göreceli Puan (GP) \\
\hline \multirow{2}{*}{ Bitki Yüksekliği (cm) } & $\leq 49$ (Zayıf) & 1 & \multirow{2}{*}{20} \\
\hline & 50 < (Güçlü) & 2 & \\
\hline \multirow{4}{*}{$\begin{array}{l}\text { Meyve Sayısı } \\
\left(\text { adet bitki }^{-1}\right)\end{array}$} & $\leq 50 \mathrm{ad}$ & 1 & \multirow{4}{*}{20} \\
\hline & $51-100$ & 2 & \\
\hline & $101-150$ & 3 & \\
\hline & $151<$ & 4 & \\
\hline \multirow{4}{*}{ Meyve Ağırlığı (g) } & $<1$ & 0 & \multirow{4}{*}{20} \\
\hline & $1-1.50$ & 1 & \\
\hline & $1.50-2.00$ & 2 & \\
\hline & $2.00<$ & 3 & \\
\hline \multirow{2}{*}{ Meyve uzunluğu (mm) } & $<60 \mathrm{~mm}$ (kısa) & 1 & \multirow{2}{*}{20} \\
\hline & $>60 \mathrm{~mm}$ (uzun) & 0 & \\
\hline \multirow{2}{*}{ Meyve Genişliği (mm) } & $\leq 15$ & 2 & \multirow{2}{*}{10} \\
\hline & $15<$ & 1 & \\
\hline \multirow{2}{*}{ Meyve Rengi } & Kırmızı & 1 & \multirow{2}{*}{10} \\
\hline & Turuncu & 2 & \\
\hline
\end{tabular}

\section{Acılık ölçümleri}

Çalışmada toplam kapsaisinoidlerin ölçümlerinde kullanılmak üzere verim denemelerinden elde edilen meyveler etüvde $65{ }^{\circ} C^{\prime}$ de72 saat süre ile kurutulmuştur. Bütün halinde kurutulan meyvelerin sap ve tohum kısımları ayıklanmış, geri kalan kısımları ögütücüden geçirilerek toz hale getirilmiştir. Öğütülmüş toz biber örneğinden $1.00 \mathrm{~g}$ alınarak sodyum asetat ile doyurulmuş \%95'lik etil alkol ile 100 mL'ye tamamlanmıştır. Örnekler $60{ }^{\circ} \mathrm{C}^{\prime}$ ye ayarlanmış su banyosunda 3 saat süre ile bekletilmiştir. Ardından 40 dakika ultrasonik küvette tutulan örnekler Whatman 2 numaralı filtre kâğıdı ile süzülmüştür. Hacmi $100 \mu \mathrm{L}$ olan şırınga ile $20 \mu \mathrm{L}$ hacimdeki Yüksek Basınçlı Sıvı Kromatografisi (HPLC) örnek yuvası doldurulmuştur. 
Kromatografi Koşulları:

Kolon :C-18 (250 $\quad x \quad 4.6 \quad \mathrm{~mm}) \quad$ Nuclesil

Macherey-Nagel Kolon

Mobil Faz : \% 48.4 metanol, \% 30.2 su \% 13.3 dioksan $\% 7.9$ asetonitril, $\% 0.2$ perklorik asit (\% 2'lik).

Akış hızı $\quad: 1.5 \mathrm{~mL} \mathrm{dk}^{-1}$

$\begin{array}{ll}\text { Toplam kapsaisinoid alanı } & =\begin{array}{l}\text { Birinci pikin } \\ \text { alanı }\end{array} \\ \text { Toplam kapsaisinoid }(\mathrm{ppm}) & =\frac{\text { ÖTKA } \times \text { STKD } \times 100}{\text { STKA }} \text { Eq.(1) }\end{array}$

ÖTKA : Örneğin toplam kapsaisinoid alanı

STKD : Stantarda ait toplam kapsaisinoid değeri (ppm)

STKA : Standarda ait toplam kapsaisinoid alanı

Hesaplanan toplam kapsaisinod miktarının 15 katsayısı ile çarpılması ile kapsaisinoid miktarı Scoville Acılık Birimine (SHU=Scoville Heat Unit) dönüştürülmüştür (Anonymous, 2004).

\section{Deneme alanının toprak özellikleri ve gübreleme programı}

Deneme alanı toprakları killi tınlı, hafif alkali, kireçli, tuzsuz ve düşük organik maddeye sahiptir. Toprakta $3.95 \mathrm{~kg} \mathrm{da}^{-1} \mathrm{P}_{2} \mathrm{O}_{5}, 66.14 \mathrm{~kg} \mathrm{da}^{-1} \mathrm{~K}_{2} \mathrm{O}, 27748 \mathrm{ppm} \mathrm{Ca}, 895$ ppm Mg, 3.30 ppm Cu, 9.93 ppm Mn, 1.72 ppm Zn bulunduğu belirlenmiştir. Analiz sonuçlarına göre biber bitkisinin üretim sezonu boyunca $14 \mathrm{~kg} \mathrm{da}^{-1}$ saf Azot, 9 $\mathrm{kg} \mathrm{da}^{-1}$ saf Fosfor ihtiyacl olduğu belirlenmiştir. Bu sonuçlara göre çiçeklenme öncesine kadar $7 \mathrm{~kg} \mathrm{da}^{-1}$ Üre (\% $46 \mathrm{~N}$ ) $4 \mathrm{~kg} \mathrm{da}^{-1}$ Monoamonyumfosfat (MAP) (\% $12 \mathrm{~N}$, \% $61 \mathrm{P}$ ), meyve olum dönemine kadar $6 \mathrm{~kg} \mathrm{da}^{-1}$ Üre, 7 $\mathrm{kg} \mathrm{da} a^{-1}$ MAP, hasada kadar $6 \mathrm{~kg} \mathrm{da}^{-1}$ Üre, $7 \mathrm{~kg} \mathrm{da}^{-1}$ MAP uygulanarak bitki besin ihtiyaçları karşılanmıştır.

\section{Deneme deseni ve istatistik analiz}

Islah programının 7. yılında (2019) durulmuş hatlar içerisinden tartılı derecelendirme ile seçilen hatlar; 8. yılında (2020) verim denemesine alınmış, tesadüf blokları deneme desenine göre 4 tekerrürlü, parselde 2 sıra, 30 bitki olacak şekilde $70 \times 30 \mathrm{~cm}$ aralık ve mesafelerde dikilmiştir. Standart bir tatlı süs biberi çeşidi bulunmadığından, denemede kontrol olarak acı BATEM Alpçelik süs biberi çeşidi kullanılmıştır. Hatlar arasındaki farklıkların önemliliği varyans analizi ile belirlenmiş, ortalamalar Tukey testi ile gruplandııılmıştır. Hesaplamalarda JMP yazılımı 5.0.1 versiyonu kullanılmıştır.

\section{BULGULAR ve TARTIŞMA}

Islah programının ilk yılında (2013) ebeveyn olarak
Enjeksiyon Hacmi: $20 \mu \mathrm{L}$

Dedektör : UV/VIS $280 \mathrm{~nm}$

Örneklerden ve standartlardan elde edilen alanlar aşağıdaki formüller yardımı ile hesaplanmıştır.

kullanılan Biquinho çeşidi tatlı olduğu halde melezlemeler sonucu elde edilen $F_{1}$ generasyonunun meyvelerinde yüksek oranda acılık görülmüştür. Yapılan acılık analizleri sonucunda "Santos Flame" çeşidinde acılık olmadığı ancak "Biquinho" çeşidinde duyusal olarak algılanamayacak kadar düşük seviyede (396 SHU) acılığın var olduğu belirlenmiş, $F_{1}$ bitkilerinin meyvelerinde ise yüksek düzeyde (15733 SHU) acılık tespit edilmiştir. Kendilenen Santos Flame $\otimes$ Biquinho melezlerinin $F_{2}$ kademesindeki 360 bitkiden yaklaşık yarısında meyve tutumu oluşmamış, dolayısı ile tohum alınamamıştır. Bunun nedeninin erkek ve dişi organların konumu, farklı zamanlarda olgunlaşması, yabancı tozlanma eğilimi ve çevresel faktörlerden kaynaklandığı tespit edilmiştir. Acılık analizleri sonucunda $F_{2}$ generasyonundaki bireylerin de meyvelerinde acılık özelliğinin devam ettiği görülmüştür. Bu nedenle ıslah programının üçüncü yılında (2015) Santos Flame çeşidinin ana, CHF-1, F66-SB ve MKÜ-69 genotiplerinin baba olarak kullanıldığı $F_{2}$ bireylerinin (Şekil 3) kendilenmesi ile elde edilen $F_{3}$ generasyonlarından (Şekil 4) döl kontrollü teksel seleksiyon yöntemi ile $F_{6}$ ve $\mathrm{F}_{7}$ kademesinde acılık içermeyen hatlar geliştirilmiştir. Islah programının 4. yılında (2016) seleksiyon kriterleri doğrultusunda seçilen $F_{4}$ kademesinde; 24 birey, $F_{3}$ kademesinde ise 6 birey olmak üzere toplam 30 tatlı genotip seçilerek sonraki yıllara aktarılmıştır. Programın 5. (2017), 6. (2018) ve 7. (2019) yılında kendilemelere devam edilmiştir. Seçimlerde kullanılan tartılı derecelendirme sınıf puanları, göreceli puanlar ve toplam puanlar Çizelge 3'te verilmiştir. Değerlendirmede bitki yüksekliği $50 \mathrm{~cm}$ üzerinde, olgun meyve rengi turuncu, meyve uzunluğu $6 \mathrm{~cm}$ ve altında, toplam meyve sayısı yüksek olan hatlar öncelikli olarak değerlendirilmiştir. Islah programının 7. yılında (2019) generasyonu ilerletilen 13 hattın tartılı derecelendirme toplam puanları 115 ile 230 arasında değişmiştir. Tartılı derecelendirme toplam puanı 230 olan üç adet tatlı süs biberi hattı $(8,9,11)$ ile BATEM Alpçelik çeşidi ile ıslah programının 8. yılında (2020) verim denemesine 
alınmıştır (Şekil 5).

Çizelge 3. Seleksiyon kriterlerine göre tartılı derecelendirmede hatlara verilen toplam puan değerleri Table 3. The weighted total score given to lines according to the selection criterion

\begin{tabular}{|c|c|c|c|c|c|c|c|c|c|c|c|c|c|c|c|c|c|c|c|}
\hline $\begin{array}{l}\text { Hat } \\
\text { No }\end{array}$ & BY & SP & GP & MS & SP & GP & MR & SP & GP & $\mathrm{MA}$ & SP & GP & $\mathrm{MU}$ & $\mathrm{SP}$ & GP & MG & SP & GP & $\begin{array}{l}\text { Toplam } \\
\text { Puan } \\
\end{array}$ \\
\hline 7 & 35 & 1 & 15 & 78 & 2 & 20 & Turuncu & 2 & 10 & 1.923 & 2 & 20 & 50 & 1 & 20 & 12 & 2 & 10 & 155 \\
\hline 8 & 60 & 2 & 15 & 152 & 4 & 20 & Turuncu & 2 & 10 & 2.377 & 3 & 20 & 60 & 1 & 20 & 10 & 2 & 10 & 230 \\
\hline 9 & 70 & 2 & 15 & 210 & 4 & 20 & Turuncu & 2 & 10 & 3.353 & 3 & 20 & 35 & 1 & 20 & 15 & 2 & 10 & 230 \\
\hline 10 & 35 & 1 & 15 & 83 & 2 & 20 & Turuncu & 2 & 10 & 2.217 & 3 & 20 & 30 & 1 & 20 & 15 & 2 & 10 & 175 \\
\hline 11 & 75 & 2 & 15 & 180 & 4 & 20 & Turuncu & 2 & 10 & 2.307 & 3 & 20 & 40 & 1 & 20 & 11 & 2 & 10 & 230 \\
\hline 12 & 30 & 1 & 15 & 78 & 2 & 20 & Turuncu & 2 & 10 & 1.063 & 1 & 20 & 45 & 1 & 20 & 11 & 2 & 10 & 135 \\
\hline 13 & 30 & 1 & 15 & 75 & 2 & 20 & Turuncu & 2 & 10 & 1.297 & 1 & 20 & 40 & 1 & 20 & 10 & 2 & 10 & 135 \\
\hline 15 & 40 & 1 & 15 & 90 & 2 & 20 & Turuncu & 2 & 10 & 2.010 & 3 & 20 & 32 & 1 & 20 & 14 & 2 & 10 & 175 \\
\hline 18 & 48 & 1 & 15 & 135 & 3 & 20 & Turuncu & 2 & 10 & 2.132 & 3 & 20 & 30 & 1 & 20 & 12 & 2 & 10 & 195 \\
\hline 21 & 35 & 1 & 15 & 87 & 2 & 20 & Turuncu & 2 & 10 & 1.820 & 2 & 20 & 32 & 1 & 20 & 15 & 2 & 10 & 155 \\
\hline 22 & 35 & 1 & 15 & 69 & 2 & 20 & Turuncu & 2 & 10 & 1.730 & 2 & 20 & 53 & 1 & 20 & 10 & 2 & 10 & 155 \\
\hline 23 & 16 & 1 & 15 & 45 & 1 & 20 & Turuncu & 2 & 10 & 1.920 & 2 & 20 & 63 & 0 & 20 & 12 & 2 & 10 & 115 \\
\hline 24 & 45 & 1 & 15 & 92 & 2 & 20 & Turuncu & 2 & 10 & 2.030 & 3 & 20 & 33 & 1 & 20 & 13 & 2 & 10 & 175 \\
\hline
\end{tabular}

BY ; Bitki yüksekliği (cm), MS ; Meyve sayısı (adet bitki $\left.{ }^{-1}\right), M R$; Meyve rengi, MA ; Meyve ağırlığı (g bitki ${ }^{-1}$ ), MU ; Meyve uzunluğu (mm), MG ; Meyve genişliği SP ;Sınıf Puanı , GP: Göreceli Puan.

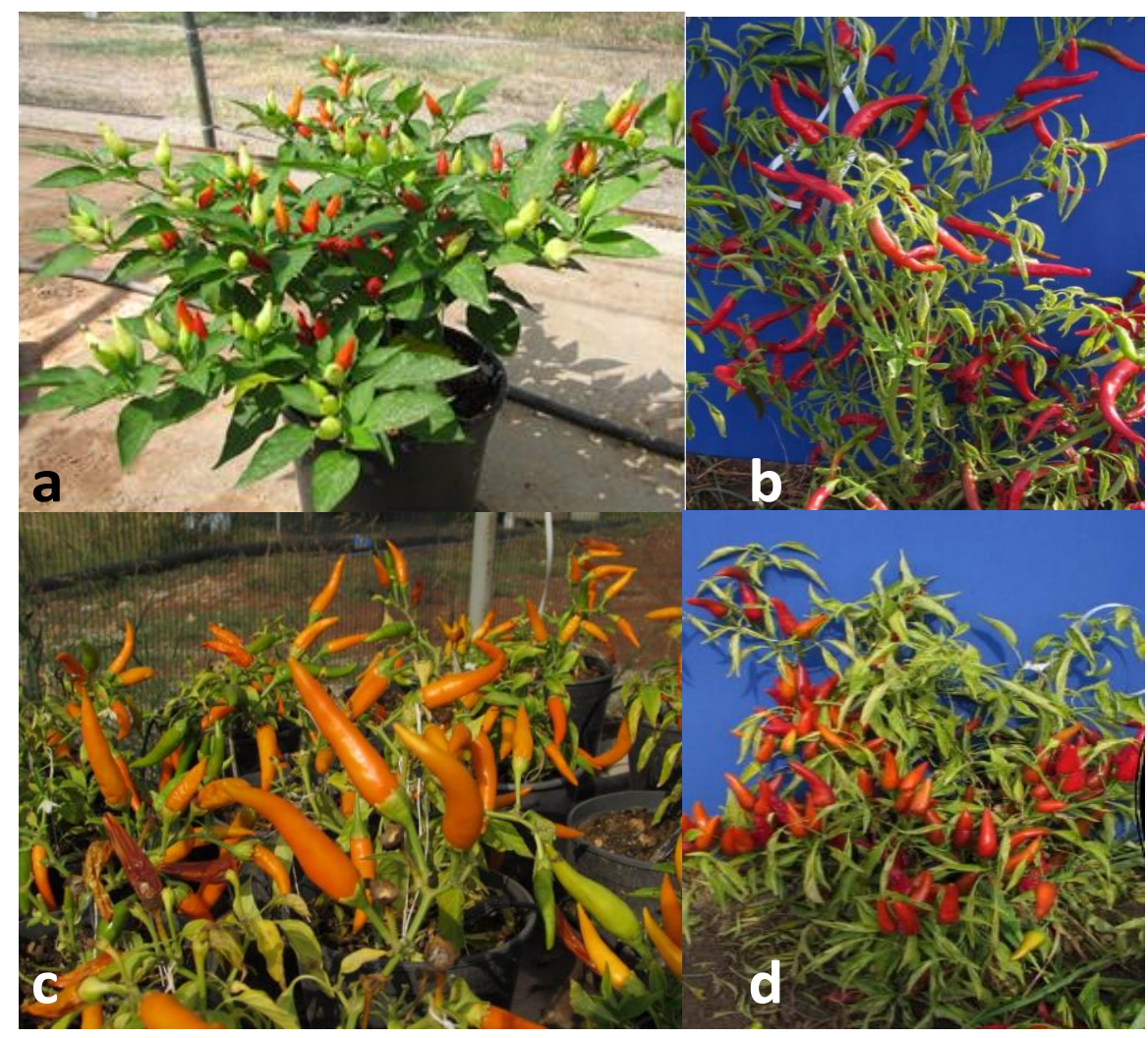

Şekil 3. Santos Flame $\otimes$ Biquinho (a), Santos Flame $\otimes$ F66-SB (b), Santos Flame $\otimes C H F-1$ (c) ve Santos Flame $\otimes$ MKÜ$69(\mathrm{~d})$ melez $\left(\mathrm{F}_{1}\right)$ bitkilerinin görünümleri.

Figure 3. The appearance of Santos Flame $\otimes$ Biquinho (a) Santos Flame $\otimes$ F66-SB, Santos Flame $\otimes C H F-1$ and Santos Flame $\otimes M K U ̈$-69 hybrid $\left(F_{1}\right)$ plants. 


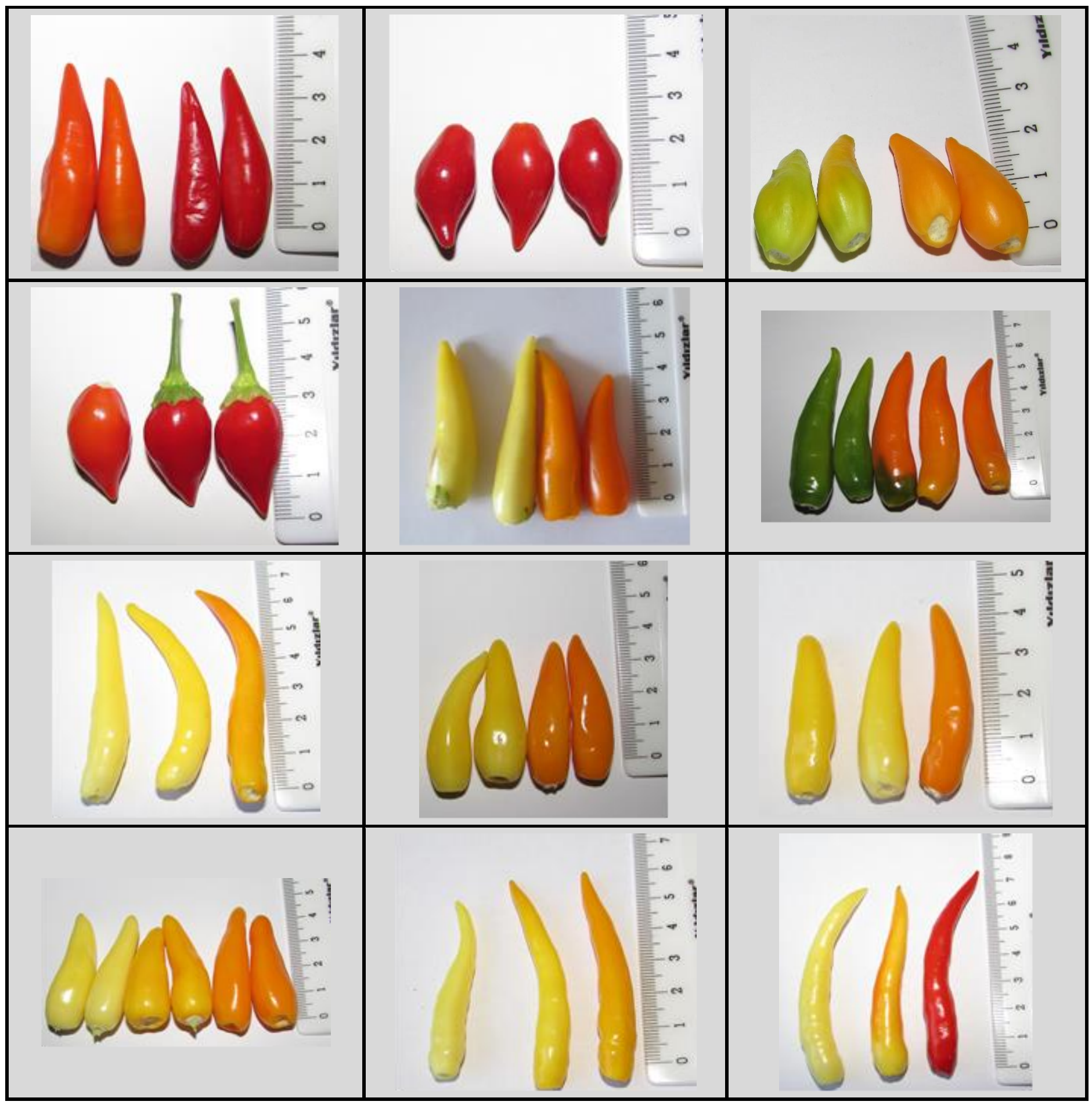

Şekil 4. Santos Flame $\otimes$ Biquinho, Santos Flame $\otimes$ F66-SB, Santos Flame $\otimes$ CHF-1 ve Santos Flame $\otimes$ MKÜ-69 melezlerinin $\mathrm{F}_{3}$ populasyonundan seçilen bazı bireylerin meyve görünümleri.

Figure 4. Fruit appearance of some individuals selected from the $F_{3}$ population of Santos Flame $\otimes$ Biquinho, Santos Flame $\otimes F 66-S B$, Santos Flame $\otimes C H F-1$ and Santos Flame $\otimes M K U-69$ hybrids. 


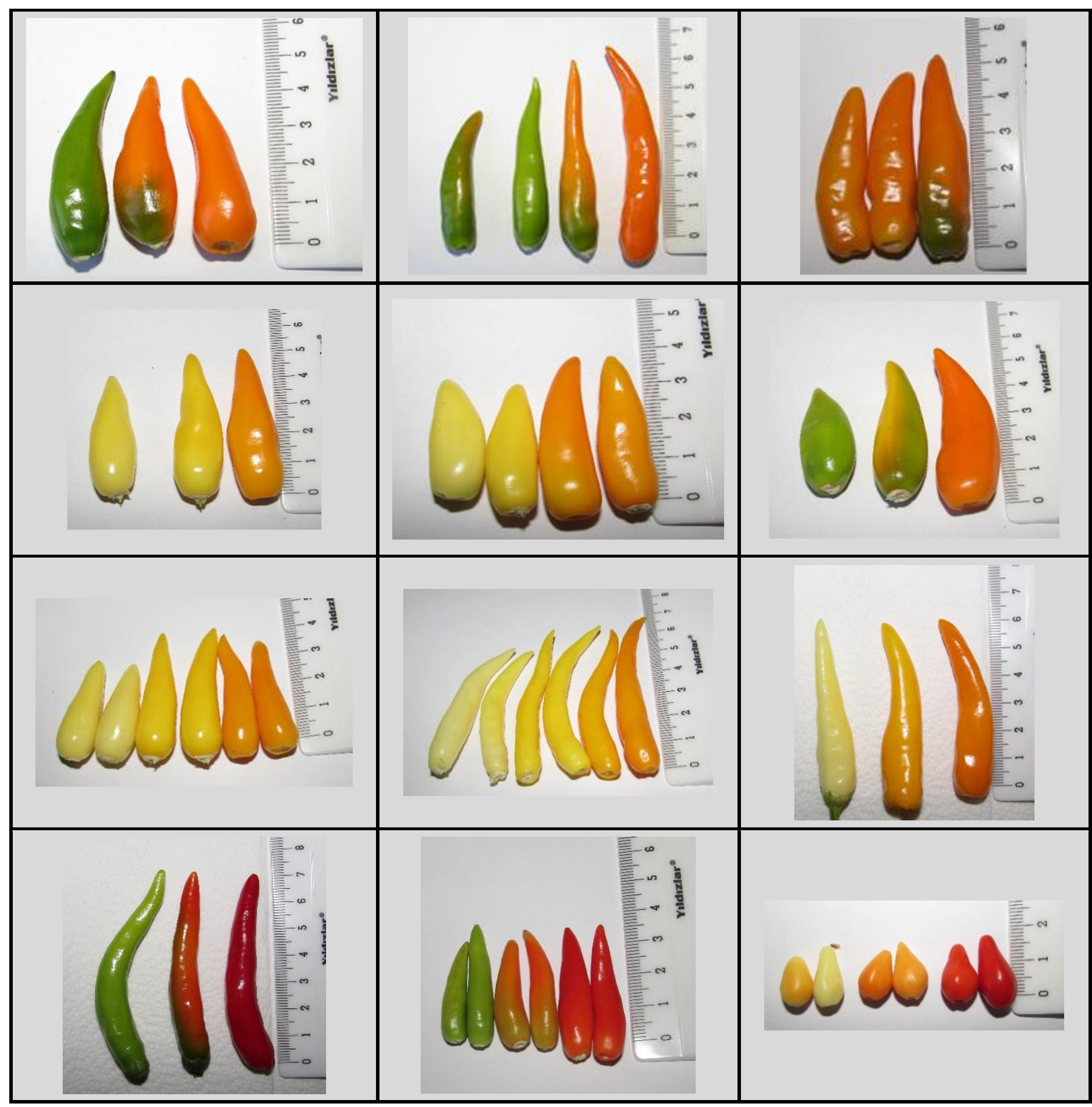

Şekil 4 (devamı). Santos Flame $\otimes$ Biquinho, Santos Flame $\otimes$ F66-SB, Santos Flame $\otimes C H F-1$ ve Santos Flame $\otimes$ MKÜ69 melezlerinin $\mathrm{F} 3$ populasyonundan seçilen bazı bireylerin meyve görünümleri.

Figure 4 (continued). Fruit appearance of some individuals selected from the F3 population of Santos Flame $\otimes$ Biquinho, Santos Flame $\otimes F 66-S B$, Santos Flame $\otimes C H F-1$ and Santos Flame $\otimes M K U-69$ hybrids. 


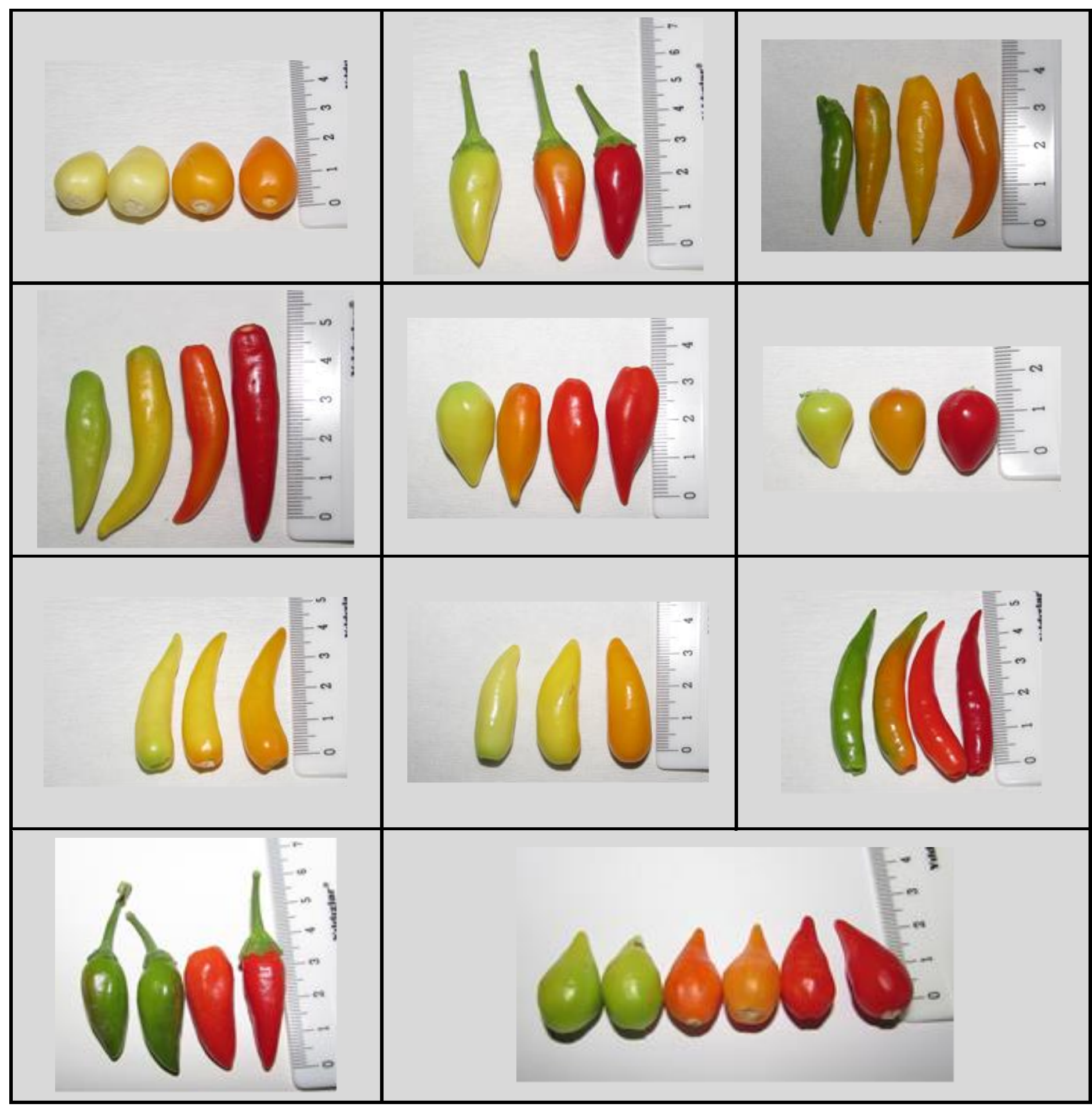

Şekil 4. Santos Flame $\otimes$ Biquinho, Santos Flame $\otimes$ F66-SB, Santos Flame $\otimes$ CHF-1 ve Santos Flame $\otimes$ MKÜ-69 melezlerinin $\mathrm{F}_{3}$ populasyonundan seçilen bazı bireylerin meyve görünümleri.

Figure 4. Fruit appearance of some individuals selected from the $F_{3}$ population of Santos Flame $\otimes$ Biquinho, Santos Flame $\otimes$ F66-SB, Santos Flame $\otimes C H F-1$ and Santos Flame $\otimes$ MKU-69 hybrids. 


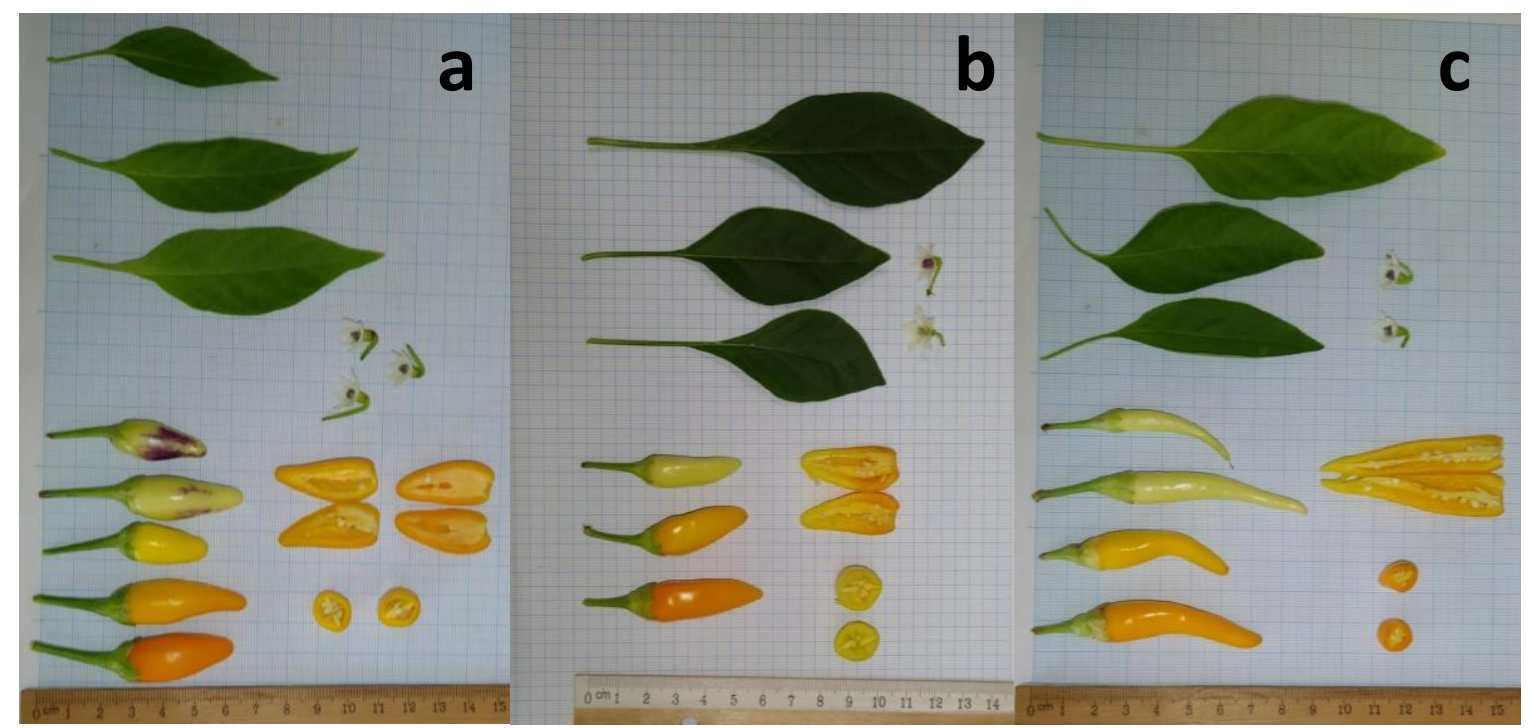

Şekil 5. Islah programı sonunda geliştirilen ve verim denemesine alınan 11 (a), 9 (b) ve 8 (c) numaralı tatlı süs biberi çeşit adayları.

Figure 5. Variety candidates of sweet ornamental pepper lines 11 (a), 9 (b) and 8 (c) improved by the breeding program and evaluated in yield trial.

Acılık, baharat olarak kullanılan biberlerde tüketici tercihlerini etkileyen önemli kalite kriterlerindendir. Biber çeşitlerinin acılık seviyelerini belirleyen kapsaisinoidler gıda sektöründe olduğu kadar kimya, ilaç ve savunma sanayisinde çeşitli kullanım alanlarına sahiptir. Bu sebeplerden dolayı yüksek acılık değerine sahip biber çeşitlerinin geliştirilmesi ıslahçıların temel hedeflerinden olmuştur (Sathiyamurthy ve ark., 2002; Bosland ve ark., 2012). Bu amaçla Bhut Jolokia (Bosland ve Baral, 2007) ve Trinidad Moruga Scorpion dünyanın en acı biber çeşitleri olarak geliştirilmiştir (Bosland ve ark., 2012). Bununla birlikte biber çeşitlerinin acllık içeriklerine kişilerin tepkilerinin oldukça farklılık gösterdiği, 300 SHU değerinin eşik algılama sınırı olduğu, acıya hassas kişilerde bu eşiğin 150 SHU olabileceği belirlenmiştir (Yemiş, 2001). Çalışmada tür içi ve türler arası melezleme yoluyla turşuluk olarak tüketime uygun ve acl olmayan biber çeşitlerinin geliştirilmesi amaçlanmıştır. Geliştirilen hatların meyve özellikleri ve verimlerine ilişkin değerleri Çizelge 4'te yer almaktadır. Kontrol olarak kullanılan BATEM Alpçelik 20 $\mathrm{mm}$ meyve uzunluğu ile en kısa meyveli genotip olurken en uzun süs biberi genotipi $52.6 \mathrm{~mm}$ meyve uzunluğu değeri ile 8 numaralı hattır. Seleksiyon kriterleri arasında yer alan $6 \mathrm{~cm}$ 'den küçük biberlerin seçimi, etkin bir seleksiyona olanak sağlamıştır. Geliştirilen 9 numaralı hat en geniş meyveye $(13.1 \mathrm{~mm})$, Hat 8 ise en dar meyveye $(9.0 \mathrm{~mm})$ sahip olmuştur. BATEM Alpçelik'in meyve eti kalınlığı 1.5 mm, Hat 9'un meyve eti kalınlığı $2.5 \mathrm{~mm}$ 'dir. Bitkide bulunan meyve sayısı 263-287 adet bitki ${ }^{-1}$ arasında değişmiş hatlar ve BATEM
Alpçelik arasında bitkide bulunan meyve sayısı bakımından farklılık görülmemiştir. Geliştirilen 9 numaralı hat en yüksek meyve ağırlığı ( $2.9 \mathrm{~g} /$ meyve), bitki başına verim (759 $\mathrm{g} \mathrm{bitki}^{-1}$ ) ve dekara verim (3581 $\mathrm{kg} \mathrm{da}^{-1}$ ) değerlerine sahip olmuştur. Bosland ve Coon (2020) tarafından Tabasco çeşidinden geliştirilen NuMex NoBasco çeşidi $2.6 \mathrm{~kg} \mathrm{bitki}^{-1}$ verime $1.2 \mathrm{~cm}$ meyve genişliğine, $4.3 \mathrm{~cm}$ meyve uzunluğuna $76.1 \mathrm{~cm}$ bitki yüksekliğine ve $0 \mathrm{SHU}$ acıllğa sahiptir (Bosland ve Coon, 2020). Meyve özellikleri bakımından NuMex NoBasco çeşidine benzer özellikler gösteren 8 ve 9 numaralı çeşit adaylarının verim değerleri bu çeşitten daha düşük bulunmuştur. Bosland ve Coon (2015) dekara $778 \mathrm{~kg}$ verimin elde edildiği, $31.0 \mathrm{~mm}$ meyve genişliği, $39.2 \mathrm{~mm}$ meyve uzunluğu ve $2.19 \mathrm{~mm}$ meyve eti kalınlığına sahip acı olmayan NuMex Trick-or-Treat çeşidini geliştirmişlerdir. Mavi ve Mavi (2015), süs biberi koleksiyonunda bulunan genotiplerin meyve sayısının 11-63 adet bitki ${ }^{-1}$, meyve genişliğinin 7.3-42.0 mm, meyve uzunluğunun 27.7-81.0 mm aralığında değiştiğini bildirmiştir. Kanal ve Balkaya (2021) C. baccatum türünde bitkideki meyve sayısı bakımından geniş bir varyasyon olduğunu belirlemiş genotiplerde bitki başına meyve sayısının 50 ile 1268 adet arasında değiştiğini bildirmiştir. Yaldız ve Özgüven (2011) süs biberi gen havuzlarında bitkideki meyve sayılarını 2-370 adet bitki1 , meyve genişliklerini $27-240 \mathrm{~mm}$, meyve uzunluklarını 17.7-106.7 mm, verimlerini ise $41.60-6427 \mathrm{~kg} \mathrm{da}^{-1}$, aralığında belirlemiştir. Araştırmada elde edilen bitkideki meyve sayıları Mavi ve Mavi (2015) ile örtüşmez iken Yaldız ve Özgüven (2011)'in bildirdiği 
aralıkta yer almıştır. Meyve genişliği değerlerinde ise aksi durum söz konusudur. Geliştirilen hatların meyve genişliği Yaldız ve Özgüven (2011)'in bildirdiği aralığa giremezken, Mavi ve Mavi (2015) tarafından belirlenen meyve genişliği değerleri ile uyum halindedir. Süs biberlerinin meyve ve bitki özelliklerinin sınıflandırılması kesin olarak yapılamadığından incelenen özellikler kullanılan popülasyonlara göre farklılıklar göstermektedir. Süs biberleri, bitki ve meyvelerin şekli, rengi ve büyüklüğü, hacmi, saksıda veya kenar bitkisi olarak kullanım amacı, kesme çiçek olarak kullanımı, taze veya kurutulmuş tüketimi, acılık dereceleri özellikleri bakımından geniş varyasyonlar gösterir. Bu varyasyonda tür farklıııkları ve türler arası melezlemeler yolu ile elde edilmiş olmaları da etkili olmaktadır (Stommel ve Bosland, 2006). Bu nedenle geliştirilen çeşitlerin özellikleri ve elde edilen değerler önceki çalışmalarla uyum içerisindedir.

Araştırmada planlanan ıslah programının başlıca amacı, acı olmayan, turşu olarak tüketime uygun süs biberi çeşit adaylarının geliştirilmesidir. Santos Flame (A) ve $\begin{array}{llllll}C H F-1 & \text { (C), F66-SB } & \text { (D) ve MKÜ-69 } & \text { (E) }\end{array}$ kombinasyonlarından döl kontrollü teksel seleksiyon yöntemi ile geliştirilen çeşit adayı 8,9 ve 11 numaralı hatlarda acılığa rastlanmamış BATEM Alpçelik çeşidinde 30350 SHU acılık ölçülmüştür. Tatlı biberler 0 SHU değeri gösterirken acl biberler 100-500 SHU'dan başlayıp 550.000 SHU değerine kadar ulaşabilir. Günümüzde dünyanın en acı biber çeșitleri 1019687 SHU acılık değeri ile Bhut Jolokia (Bosland ve Baral (2007) ve 2009231 SHU acılığa ulaşan Trinidad Moruga Scorpion'dur (Bosland ve ark., 2012). Islah programları ile acı biber çeşitleri geliştirilebildiği gibi acılık özelliği göstermeyen çeşitlerin de ıslah edilmesi önem taşımaktadır. Bosland ve Coon (2015) C. chinense türüne giren $300000 \mathrm{SHU}$ acılık değerine sahip Orange Habanero ile acılık içermeyen NMCA 30036 genotipini melezlemiş Orange Habanero ile bir geriye melez generasyonundan 5 generasyon kendileme ile acı olmayan NuMex Trick-or-Treat çeşidini geliştirmiştir. Bosland ve Coon (2020) C. frutescens türü içerisinde yer alan $30000 \mathrm{SHU}$ acılığa sahip sos ve turşu üretiminde kullanılan Tabasco çeşidi ile acı olmayan CATIE 9838 genotipinden geriye melezlemeler yaparak 7 generasyon tek bitki kendilemeleri ile acı olmayan NuMex NoBasco çeşidini geliştirmişlerdir. Benzer şekilde Tayland orijinli $\mathrm{CH}-19$ acl biber çeşidinden kendileme ve seleksiyonlar ile $\mathrm{CH}-19$ Sweet biber çeşidini geliştiren Yazawa ve ark. (2004), çok az acılık içeren bu çeşidin kapsaisinoid benzeri vanilil alkol ve kapsaisin analogları barındırdığından bahsetmişlerdir. Geliştirilen hatların meyvedeki tohum sayısı BATEM Alpçelik çeşidi ile kıyaslandığında oldukça düşük bulunmuştur. Hatlara ait meyvelerde ortalama 24-26 adet arasında tohum oluşurken bu sayı BATEM Alpçelik'te 45 olarak belirlenmiştir. Mavi ve Mavi (2015), tohumla çoğaltılmaları nedeni ile süs biberlerindeki tohum sayısının önemini vurgulamış araştırmalarında yer alan genotiplerdeki tohum sayısının 7-57 adet meyve ${ }^{-1}$ aralığında olduğunu bildirmiştir. Biber tohumları önemli yağ ve protein kaynağıdır. Meyvede bulunan yağın neredeyse tamamına yakını tohumlarda bulunmaktadır (Chen ve Lott, 1992). Turşuya işlenen süs biberleri tohumları ile tüketildiğinden meyvede tohum sayısının yüksekliği biber turşusunun besin değerini arttırmaktadır. Bununla birlikte tohum sayısının artması biber turşusunun yeme kalitesini düşürmektedir. Olgunlaşma ile birlikte tohumlar sertleşmekte ve tüketici tercihlerini olumsuz yönde etkileyebilmektedir. Turşuluk süs biberlerinde yeme kalitesini olumsuz yönde etkileyen diğer bir özellik ise meyve sapının büyüklüğüdür. Geliştirilen 8 nolu çeşit adayı $2.16 \mathrm{~g}$ saplı, $1.91 \mathrm{~g}$ sapsız meyve ağırlığına, 9 nolu çeşit adayı ise $2.88 \mathrm{~g}$ saplı, $2.59 \mathrm{~g}$ sapsız meyve ağırlığı özelliklerine sahiptir. BATEM Alpçelik en düşük meyve sapı ağırlığına sahip genotip olmuştur. Ancak sapsız meyve ağırlığının saplı meyve ağırlığına oranı olan meyve ağırlık indeksi değerleri göz önüne alındığında 9 numaralı hattın meyvesinin yenilen kısmının toplam meyve ağırlığına oranının yüzde 90 olduğu anlaşılmaktadır. Bu oranın en düşük olduğu genotip ise 11 numaralı hat olmuştur. Bu hatta ait meyvelerin yenilen kısmının toplam meyve ağırlığına oranı yüzde 85 olarak belirlenmiştir. Meyve ağırlığının toplam meyve ağırlığına oranı en yüksek olan çeşit adayı olan 9 numaralı hattan en fazla bitki başına verim ve dekara verim alınmış bu hat dekara en fazla sapsız meyve verimi değeri göstermiştir. 
Çizelge 4. Geliştirilen turşuluk biber hatlarının meyve özellikleri ve verime ilişkin değerleri

Table 4. Fruit characteristics and yield values of developed pickled pepper lines

\begin{tabular}{|c|c|c|c|c|c|c|c|c|c|c|c|c|c|c|c|c|}
\hline Çeşit/Hat & $\mathrm{MU}$ & & MG & & MEK & & MS & & MA & & BBV & & DV & & $\mathrm{SHU}^{*}$ & \\
\hline Hat 9 & 36.5 & $\mathrm{~b}$ & 13.1 & $\mathrm{a}$ & 2.5 & $a$ & 263 & & 2.9 & $\mathrm{a}$ & 759 & $\mathrm{a}$ & 3581 & a & 0 & \\
\hline Hat 8 & 52.6 & a & 9.0 & c & 1.7 & c & 274 & & 2.2 & $b$ & 598 & $a b$ & 2825 & $a b$ & 0 & \\
\hline Hat 11 & 32.2 & c & 12.3 & $b$ & 2.1 & $b$ & 280 & & 2.4 & $b$ & 629 & $a b$ & 2968 & $a b$ & 0 & \\
\hline BATEM Alpçelik & 20.0 & $\mathrm{~d}$ & 12.0 & $b$ & 1.5 & c & 287 & & 1.5 & c & 427 & $b$ & 2015 & $b$ & 30350 & \\
\hline Çeşit/Hat & & TS & & SMA & & & MSA & & $\mathrm{MA}$ & & & BBSV & & & SV & \\
\hline Hat 9 & & 26 & $b$ & 2.6 & a & & 0.3 & $b$ & 90 & & $a$ & 681 & $\mathrm{a}$ & & 214 & $a$ \\
\hline Hat 8 & & 26 & $b$ & 1.9 & b & $b$ & 0.3 & $b$ & 88 & & $b$ & 528 & $a b$ & & 491 & $a b$ \\
\hline Hat 11 & & 24 & $b$ & 2.0 & b & $b$ & 0.4 & $a$ & 85 & & c & 529 & $a b$ & & 495 & $a b$ \\
\hline BATEM Alpçelik & & 45 & a & 1.3 & $c$ & & 0.2 & C & 88 & & $b$ & 376 & $b$ & & 776 & $b$ \\
\hline
\end{tabular}

MU ; Meyve uzunluğu (mm), MG ; Meyve genişliği (mm), TS ; Tohum sayısı (adet meyve-1) MS ; Meyve sayısı (adet bitki $\left.{ }^{-1}\right), M A$; Meyve ağırlığı (g bitki $\left.{ }^{-1}\right), B B V$; Bitki başına verim (g bitki $\left.{ }^{-1}\right), D V$ : Verim (kg da $\left.{ }^{-1}\right)$, SHU ; Scoville Acılık Birimi (Scoville Heat Unit) ${ }^{*}$ Hatlarda acılık bulunmadığından çoklu karşılaştırma testi yapılmamıştır TS ; Tohum sayısı (adet meyve $\left.{ }^{-1}\right)$ MS ; Meyve sayısı (adet bitki $\left.{ }^{-1}\right)$, SMA ; Sapsız Meyve ağılığı (g bitki $\left.{ }^{-1}\right)$, MSA ; Meyve Sapı ağıllığı (g bitki $\left.{ }^{-1}\right)$, MAI ; Meyve ağılık indeksi (\%) ${ }^{* *}$ Sapsız meyve ağırlığının meyve ağırlığına oranıdır, BBSV ; Bitki başına sapsız verim (g bitki $\left.^{-1}\right)$, DSV: Sapsız Verim $\left(\mathrm{kg} \mathrm{da}^{-1}\right)$.

Sonuç olarak, araştırma sonucunda turşu sanayisinde değerlendirilmek üzere verimli yeni tatlı süs biberi çeşit adayları geliştirilmiştir. BATEM Alpçelik çeşidi ile kıyaslandığında 8 nolu hattın yaklaşık \% 40, 9 nolu hattın ise \% 77 oranında daha verimli olduğu bulunmuştur. Çeşit adaylarının özellikle acı biber tüketemeyen kişiler için alternatif olması beklenmektedir. Geliştirilen süs biberi çeşit adayları tatlı olduğundan karışık turşular içerisinde (lahana, kornişon, havuç vb. diğer sebzelerle) kolaylıkla kullanılabilecektir. Bunun yanı sıra ıslah edilen çeşit adayları süs bitkileri sektöründe, saksılı süs bitkisi şeklinde de değerlendirilebilir. Geliştirilen 8 ve 9 nolu iki çeşit adayının tescil edilmesi planlanmaktadır.

\section{ÖZET}

Amaç: Bu çalışmanın amacı, tür içi ve türler arası melezleme yolu ile kapsaisinoid içermeyen tatlı turşuluk süs biberi hatları geliştirmektir.

Yöntem ve Bulgular: Çalışmada yabancı orijinli iki süs biberi çeşidi Biquinho (Capsicum chinense Jacq. ) ve Santos Flame (Capsicum annuum L.) ile üç tatlı biber genotipinin (MKÜ-69, F66-SB ve CHF-1) kombinasyonu ile oluşturulan melez bahçesinden döl kontrollü teksel seleksiyon yöntemi ile acı olmayan, tek seferde tüketilebilecek boyutta, verimi yüksek, turşuluk süs biberi hatları geliştirilmiştir. Ebeveyn, melez ve geliştirilen biber hatlarının kapsaisin içerikleri Yüksek Basınçlı Sıvı Kromatografisi ile belirlenmiş ve Scoville
Acılık Birimine (SHU) dönüştürülmüştür. Santos Flame çeşidinde acılık olmadığı ancak Biquinho çeşidinde duyusal olarak algılanamayacak kadar düşük düzeyde (396 SHU) acılığın var olduğu, F1 bitkilerinin meyvelerinde ise yüksek seviyede (15733 SHU) acılık oluştuğu tespit edilmiştir. Bu kombinasyondan elde edilen $F_{3}$ bireylerinin meyvelerinde acılığı oluşturan karakterlerin devam etmesi sebebi ile generasyon ilerletilmemiştir. Santos Flame çeşidinin ana, MKÜ-69, F66-SB ve CHF-1 genotiplerinin ise baba olarak kullanıldığı kombinasyonlardan 4 adet $\mathrm{F}_{6}$ kademesinde turşuluk tatlı süs biberi hattı geliştirilmiştir. Geliştirilen 8 nolu açık tozlanan çeşit adayı $60 \mathrm{~cm}$ bitki boyu, 52.6 $\mathrm{mm}$ meyve boyu, $9.0 \mathrm{~mm}$ meyve eni, $2.16 \mathrm{~g}$ saplı meyve ağırlı̆ı ve $1.91 \mathrm{~g}$ sapsız meyve ağırlığına sahiptir. Meyve sayısı 274 adet bitki $^{-1}$ ve ortalama verimi $598 \mathrm{~g} \mathrm{bitki}^{-1}$ olarak belirlenmiştir. 9 nolu çeşit adayı ise $70 \mathrm{~cm}$ bitki boyu, $36.5 \mathrm{~mm}$ meyve uzunluğu, $13.12 \mathrm{~mm}$ meyve genişliği, $2.88 \mathrm{~g}$ saplı meyve ağırlığı ve $2.59 \mathrm{~g}$ sapsız meyve ağırlığı özelliklerine sahiptir. Ortalama meyve sayısı 263 adet bitki ${ }^{-1}$ ve ortalama verimi $759 \mathrm{~g} \mathrm{bitki}^{-1}$ ve $3581 \mathrm{~kg} \mathrm{da}^{-1}$ dır.

Genel Yorum: Türler arası melezlemelerde aktarılmak istenen karakter bakımından benzerlik gösteren ebeveynler genetik olarak birbirlerine uzak olmaları nedeni ile acılık karakteri dikkate alındığında generasyonlarda açılımlar meydana getirmektedir. Çalışmanın Önemi ve Etkisi: Çalışma sonucunda turşuluk acı biber çeşitlerine alternatif, acılık bileşenlerinin bulunmadığı tek seferde tüketilebilecek 
büyüklükte tatlı süs biberi hatları geliştirilmiştir.

Anahtar Kelimeler: Capsicum annuum, Capsicum chinense, süs biberi, turşu, acılık.

\section{TEŞEKKÜR}

Bu çalışma T.C. TARIM VE ORMAN BAKANLIĞı Tarımsal Araştırmalar ve Politikalar Genel Müdürlüğü tarafından finansal olarak desteklenmiştir (Proje Numarası: TAGEM /BBAD/15/A09/P02/03).

\section{ÇIKAR ÇATIŞMA BEYANI}

Yazar(lar) çalışma konusunda çıkar çatışmasının olmadığını beyan eder.

\section{ARAŞTIRMACILARIN KATKI ORANI BEYANI}

Yazarlar çalışmaya eşit oranda katkı sağlamış olduklarını beyan eder.

\section{KAYNAKLAR}

Anonim (2020) Yıllık sanayi ürün istatistikleri turşu satış miktarı. https://data.tuik.gov.tr/Kategori/GetKategori?p=tari m-111\&dil=1 (Erişim Tarihi: 06/11/2020).

Anonymous (2004) ASTA (The American Spice Trade Association), Method 21.3. Pungency of Capsicum and their oleoresins (HPLC method- preferred), Revised October 2004).

Anonymous (2021) FAOSTAT, Word Production Data. Retrieved May 30, 2021, from http://www.fao.org/faostat/en/\#data/QC

Bosland PW, Baral JB (2007) 'Bhut Jolokia'-The world's hottest known chile pepper is a putative naturally occurring interspecific hybrid. HortScience 42(2): 222-224.

Bosland PW, Coon D (2015) 'NuMex Trick-or-Treat', a no-heat Habanero pepper. HortScience 50(11): 1739-1740.

Bosland PW, Coon D (2020). NuMex NoBasco: A noheat tabasco-type chile pepper. HortScience 55(5): 741-742.

Bosland PW, Votava EJ, Votava EM (2012) Peppers: vegetable and spice capsicums. (Vol.22). Cabi.

Chen P, Lott JN (1992) Studies of Capsicum annuum seeds: structure, storage reserves, and mineral nutrients. Canadian Journal of Botany 70(3): 518529.

Collins M, Bosland P (1994) Rare and novel capsaicinoid profiles in Capsicum. Capsicum Eggplant Newsletter 13: 48-51.
Greenleaf WH (1986) Pepper breeding. In: Breeding Vegetable Crops, (M.J. Bassett Ed.), AVI Publishing Co. Inc., Westport, Connecticut, USA. pp. 67-133.

Kanal A, Balkaya A (2021) Capsicum baccatum türüne ait biber popülasyonunun karakterizasyonu ve morfolojik varyasyon düzeyinin belirlenmesi. MKU Tar. Bil. Derg. 26(2): 278-291.

Mavi K, Mavi F (2015) Bazı süs biberi genotiplerinin tohumluk bitki özellikleri ve tohum çıkış performansları. Dicle Üniversitesi Fen Bilimleri Enstitüsü Dergisi 4(1): 31-35.

Reifschneider FJB, Ribeiro CDC, de Carvalho SIC (2013) Development of new Capsicum cultivars at EMBRAPA (Brazil). In Embrapa Hortaliças-Artigo em anais de congresso (ALICE). In: Meeting On Genetics and Breeding of Capsicum and Eggplant EUCARPIA 15.

Sathiyamurthy VA, Veeraragavathatham $D$, Chezhiyan $\mathrm{N}$ (2002) Studies on the capsaicin content in chilli hybrids. Capsicum and Eggplant Newsletter 21: 4447.

Stommel JR, Bosland PW (2006) Pepper, ornamental, Capsicum annuum. In Flower breeding and genetics: Issues, challenges and opportunities for the 21st century. Springer, (N.O. Anderson, Ed.) Dordrecht, The Netherlands, pp 561-599.

Thresh LT (1846) Isolation of capsaicin. Pharmaceutical Journal 6: 941.

Yaldız G, Özgüven M (2011) Farklı süs biberi (Capsicum sp.) tür ve hatlarının Çukurova koşullarına adaptasyonu. Yüzüncü Yıl Üniversitesi Tarım Bilimleri Dergisi 21(1): 1-11.

Yazawa S, Suetom N, Okamoto K, Namiki T (1989) Content of capsaicinoids and capsaicinoid-like substances in fruit of pepper (Capsicum annuum L.) hybrids made with' $\mathrm{CH}-19$ Sweet' as a parent. Journal of the Japanese Society for Horticultural Science 58(3): 601-607.

Yazawa S, Yoneda H, Hosokawa M, Fushiki T, Watanabe $T$ (2004) Novel capsaicinoid like substances in the fruits of new non-pungent cultivar 'CH-19 Sweet' of pepper (Capsicum annuum). Capsicum and Eggplant Newsletter 23: 17-20.

Yemiş O (2001) Kırmızı biberlerden oleoresin capsicum üretimi üzerine araştırma. Yüksek Lisans Tezi, Ankara Üniversitesi Fen Bilimleri Enstitüsü, Gıda Mühendisliği ABD, 71. 